\title{
El tránsito de Venus en el Observatorio Astronómico Centroamericano de Suyapa (OACS)"
}

María de Jesús Quiróz Medina

\section{Resumen}

Este documento tiene como objetivo describir la forma en que se vivió el evento TRÁNSITO DE VENUS en el Observatorio Astronómico Centroamericano de Suyapa de la Facultad de Ciencias Espaciales (OACS/FACES/UNAH), un evento astronómico que sucede cuando venus pasa directamente entre el sol y la Tierra y luce como un pequeño punto negro que atraviesa la cara visible del sol durante un tiempo de entre 5 y 8 horas. Este evento se observó el día martes 5 de Junio de 2012 entre las 16 y las 18 horas. Los medios de comunicación llegaron al OACS para obtener y dar a conocer al público información acerca del evento. Debido a que las condiciones climatológicas no parecían favorables para Tegucigalpa, un equipo de astrónomos viajó a la aldea de mbo Creek, Ciudad de la Ceiba y otro equipo se quedó en Tegucigalpa. Ambos equipos trabajaron en forma coordinada para lograr los objetivos propuestos.

Palabras clave: Tránsito de venus, eclipse, OACS-eclipse, observación del Sol.

\section{Abstract}

On June 5, 2012, a major event in astronomy history was observed, as mankind witThis paper aims to describe the way the TRANSIT OF VENUS event took place in the Central American Astronomical Observatory of Suyapa, Faculty of Spatial Sciences (OACS / FACES / UNAH), an astronomical event that occurs when Venus passes directly between the sun and Earth and looks like a small black dot crossing the visible face of the sun for a time of 5 to 8 hours. This event was observed on Tuesday, June 5, 2012 between 16 and 18 hours. The media came to OACS to obtain and disseminate public information about the event. Because not seem favorable weather conditions favorable to Tegucigalpa, a team of astronomers tra- 
veled to the village of Sambo Creek, City of Ceiba and other equipment remained in Tegucigalpa. Both teams worked in concert to achieve the objectives.

Keywords: Transit of Venus, OACS - eclipse observation of the sun

María de Jesús Quiróz Medina (mariatesis1@yahoo.es) Universidad Nacional Autónoma de Honduras. Facultad de Ciencias Espaciales. Departamento de Astronomía y Astrofísica. 


\section{Introducción}

Un tránsito planetario se da cuando un planeta cruza delante de una estreIla. En la Tierra se pueden observar los tránsitos de Mercurio y Venus ya que son los planetas interiores que pueden pasar frente al Sol. El 5 de Junio de 2012, la humanidad observó el tránsito de Venus.

Cuando Johannes Kepler publicó las tablas rudolfinas del movimiento planetario en 1627, esto le permitió hacer detalladas predicciones de futuras posiciones e interesantes alineamientos de planetas, descubrió que ambos Mercurio y Venus transitaban el disco del Sol en 1631. Kepler murió antes del tránsito pero le sobrevivió el astrónomo francés Pierre Gassendi quien fue testigo del tránsito de mercurio predicho.

En 1677 Edmond Halley observó un tránsito de Mercurio y descubrió que los tránsitos de planetas podrían ser usados para calcular la distancia Tierra sol.

El evento acaparó la atención mundial, pero también de los hondureños, debido a que hasta el año 2125 los hondureños tendrán la oportunidad de observar otro tránsito de Venus. En el año 2117 el evento ocurrirá pero no será observable desde Honduras pues sucederá durante la noche.

\section{Descripción}

Unas semanas antes de la ocurrencia del evento, los medios de comunicación y público en general de todas las edades abarrotaron las instalaciones de la Facultad de Ciencias Espaciales en busca de información relacionada con el evento.

Los astrónomos del OACS prepararon el material y equipo astronómico para que las personas observaran el evento de manera segura.

\section{Materiales y método}

Para lograr el impacto esperado en la población hondureña en la observación de este evento astronómico, los astrónomos del OACS monitorearon las condiciones meteorológicas y se tomó la decisión de enviar un equipo de observación a la zona norte de Honduras, se escogió la aldea de Sambo Creek por contar con 
hoteles que tienen mirador y servicio de internet. En el hotel Canadien se brindaron condiciones para para instalar el equipo, hacer observaciones y tomar los datos. Un grupo de más de doscientas personas entre miembros de la comunidad, dueños, huéspedes y empleados del hotel observaron el evento.

Se tomaron Imágenes del evento que fueron enviadas luego vía correo electrónico a Tegucigalpa, para que los espectadores que esperaban ansiosos el evento las pudieran observar proyectadas en la pared

Debido a que en Tegucigalpa las condiciones climatológicas no fueron favorables. Se utilizaron las siguientes estrategias para observar el evento de manera segura:

- Se habilitó una página web dedicada a la observación del tránsito (http://faces. unah.edu.hn/transitovenus/). Para que las personas observaran el evento desde su casa, oficina o cibercafé.

- Observación por medio de telescopios con la técnica de proyección

- Utilización del "embudo solar": (Fienberg, 2012) en este caso, se coloca un embudo directamente sobre el ocular. Sobre su apertura se coloca una pantalla translucida donde se proyecta la imagen.

La observación directa del tránsito mediante un filtro \#14 de soldador.

\section{Bibliografía}

- Chou, B. (Enero de 1999). Recuperado el 5 de Mayo de 2012, de http://www. kkohki.com/products/SolarSafety/DrRalphChouSolarSafety.pdf

- UTIC channel / youtube.com. (s.f.). Obtenido de http://www.youtube.com/watch?v=4RGr9FcBrSM\&feature=youtu.be

- http://www.skyandtelescope.com/observing/highlights/134332798.html

- http://eclipse.gsfc.nasa.gov/OH/tramsit12.html 